\title{
Knowledge Integration in Collaborative New Product Development of Large Commercial Aircraft of China
}

\author{
Li Zhengfeng, Senior Member, IACSIT
}

\begin{abstract}
The aim of this paper was to explore the acquisition, integration and use of new knowledge from multiple sources to promote $R \& D$ process of large commercial aircraft of China. Based on interviews of actors participated R\&D of aircraft, it constructed a knowledge portal centered with knowledge repository of $\mathrm{C} 919$ program. The knowledge portal was analyzed in multiple subsystems comprised of layered structures. Each subsystem had a multi-layered knowledge integration architecture to dynamically integrate diverse knowledge within the Co-NPD network. Three types of interfaces and relative collaborative mechanisms across multi-levels were found in collaboration process. These collaborative mechanisms created norms to provide assurance that "proprietary knowledge" can be effectively protected while at the same time encourage valuable knowledge to be freely shared and utilized.
\end{abstract}

Index Terms-Collaborative new product development, knowledge integration, network, collaborative mechanisms.

\section{INTRODUCTION}

Like many companies in the aerospace industry, the Commercial Aircraft Corporation of China (COMAC) is to meet the complex challenges and experience an accelerated rate of changes. Customer expectations are increasing, and in response, COMAC must develop more economical efficiency and inexpensive aircrafts to deal with fierce competitions. So it is necessary to maximize its capabilities to find innovative solutions to adapt to the demands and a constantly changing marketplace. In the process of developing new products, plenty of obstacles and problems need to be overcome. For example, how to integrate knowledge and skills among participants is one of the most important obstacles. COMAC increasingly relies on joint R\&D projects with other firms, universities or research institutions which are becoming more engaged as active partners in Co-NPD of large commercial aircraft. However, the fundamental purpose of academic research is to "produce codified theories and models that explain and predict natural realities", while R\&D practice of COMAC is concentrated on designing and developing "safety, economic and comfortable aircraft". Furthermore, for each member in Co-NPD network, the criteria used by each specialist are private to them in that they are complex and concerned with their particular technologies. Therefore, trade-offs and negotiations are required to make the actors' efforts coherent.

In this paper, Co-NPD is defined as the process in which

Manuscript received December 12, 2013; revised February 17, 2014.

$\mathrm{Li}$ Zhengfeng is with the the School of Management at Northwestern Polytechnical University, China (e-mail: lizhengfeng@ nwpu.edu.cn). actors from disciplines share their knowledge about both the development process and its content. They do that in order to create shared understanding on both aspects, to be able to integrate and explore their knowledge, and to achieve the larger common objective. For the collaborative R\&D process of large commercial aircraft, it means that every $R \& D$ participant need to cross the single knowledge boundary to absorb more knowledge resources, and disseminate new knowledge simultaneously to the R\&D network including interdependent enterprises, universities and other relative organizations. Davenport and Prusak [1] have identified effective communication of knowledge both internally and externally through knowledge network as a key element in transforming organizational NPD. Therefore, the aim of this paper is to explore the acquisition, integration and use of new knowledge from multiple sources in the $R \& D$ process of large commercial aircraft. There will be a particular focus on the need to develop appropriate Knowledge portal and model as a key element to boost the aircraft R\&D performance.

\section{THEORETICAL BACKGROUND}

The research about collaborative new product development (Co-NPD) mainly focused on how to use the information systems and techniques to support collaborative work among actors, and solve the conflicts in the process of collaborative new product development. Some literatures indicated that positive outcomes and performance enhanced relating to organizing for collaboration. New knowledge, information diffusion, creative breakthroughs, social change, and flexibility are important outputs of collaboration [2]. For example, Mishra [3] found that in the new product development, collaborative competence had a direct impact on project performance, but its impact on market performance was indirect, mediated through project performance. Ayers [4] demonstrated the importance of promoting collaborative relationships between $R \& D$ and marketing through the findings from a survey of 152 product managers, and found such relationships could be fostered by decentralizing decision making and clarifying the roles of new product development personnel. Bstieler [5] studied the trust formation in collaborative new product development and showed that a higher level of trust clearly differentiates between high performance and low performance collaborative relationships in new product development. Lam [6] built a coordination mechanism model of Co-NPD process to solve the issues such as low efficiency, high cost of product design, heavy loss caused by rework and so on.

Recently both executives and academics have identified 
knowledge integration as perhaps the key factors in implementing knowledge management successfully and achieving new product development goals. Knowledge integration was the pivotal role of transferring explicit knowledge to the other members in the organization. According to Bartol [7], the main requirements of knowledge integration and sharing were social circumenstances, organizational conditions, and technological conditions. Liu [8] thought that knowledge integration process was composed of knowledge externalization through knowledge resources and internalization of it by its receivers. In this process, people acquired their needed knowledge not only by internal organizational sources, but also used external sources. Although the focus of much of the knowledge integration and sharing literature was on the individual organization as the unit of analysis, there was increasing evidence which suggested that a "network" of firms, universities, and research institutions also can achieve high performance of new product development through collaboration. Recent studies had shown barriers to knowledge integration behaviors, while other studies had produced empirical evidences on the benefits of this kind of arrangement [9]. Bond [10] observed that in the aircraft industry the locus of innovation was the network, not the individual firm. Patents were typically filed by a large number of individuals working for a number of different organizations, including Boeing and Airbus firms, GE engineer and CFM companies, Honeywell and Chinese Avic corporations, and universities. McAdam [11] suggested the importance of collaborative knowledge sharing within composite new product development. They found that it was essential that knowledge from multiple sources was effectively integrated in the process of NPD using a designated knowledge portal.

In fact, although there have been considerable discussions on the topic of knowledge integration in organizational or collaborative new product development, there is little detailed study of the operation and process through which multiple knowledge sources is effectively integration and sharing. How do firms implement knowledge integration in the collaborative network? How do firms in a knowledge-sharing network solve problems inherent in knowledge integration? To answer these questions is our main research objectives.

\section{KNOWLEDGE INTEGRATION PORTAL IN CO-NPD NETWORK OF AIRCRAFT}

In our exploratory study, the Co-NPD network is consisted of the group of firms and academic institutions which collaborate to develop and manufacture an aircraft. The C919 program and sub-programs are the central or core position in the network because 1) the R\&D pattern is based on the "airframer-suppliers" model to build a system of both national and international suppliers, and 2) all $R \& D$ activities and subcontracts to increase the efficiency of the entire value chain network are coordinated surrounded C919 program. In the program, the collaboration of prime aerospace manufacturers may provide new industry standards and quality criteria for future development. Other participants need to leverage previous experience in new process and product development, benchmark best practice in the industry sector, and communicate new knowledge between academic and industrial bases. Now in the aircraft R\&D process, IT-enabled techniques and tools play the most important role in contemporary aerospace companies. Three dimensional CAD, CAM, and computer aided engineering (CAE) software programs are in common use to reduce time and cost constraints in Co-NPD by reducing or eliminating the need for physical mock-ups, expensive wind tunnel testing, and so on. While, the aircraft $R \& D$ in this environment requires cross-functional internal and external collaboration, with frequent, reciprocal, and early communication of knowledge realized in a centralized platform and system. According to the models of McAdam [11], this paper constructs a knowledge portal and system for Co-NPD of large commercial aircraft shown as Fig. 1.

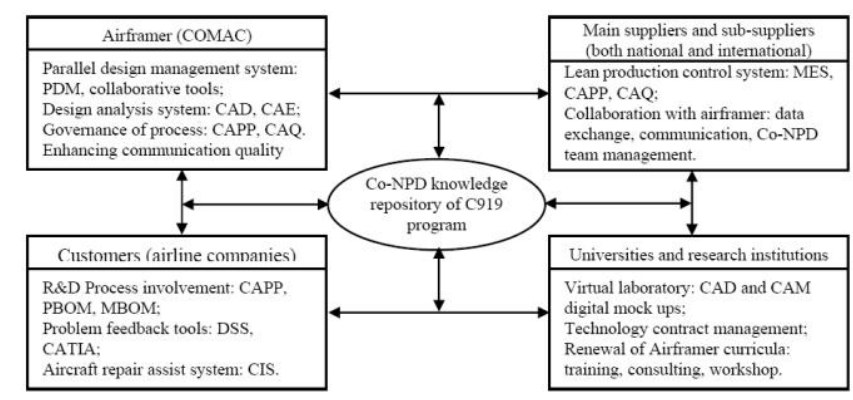

Fig. 1. Knowledge portal and system for Co-NPD of large commercial aircraft of China.

The aim of this Knowledge portal and system inferred that internal and external knowledge from multiple sources must be acquired, embedded, integrated and used to drive the R\&D process via systematically collaboration among all participants. The framework and its content were probed by COMAC and some collaborators through interviews with a number of engineers, managers and university lectures from Company-University partnerships. In this portal, COMAC coordinated R\&D activities of all firms in the systems. As the Airframer, COMAC had been designed to incorporate key NPD principles, namely: parallel design management, design analysis, governance of process, and enhancing the quality of interfaces and communication with all collaborators. In order to support schedule, cost, technical parameters, and program definition, it required that COMAC pursued parallel design management systems using techniques such as PDM and other collaborative tools. The company's approach to benchmark the sub- modularity was named design analysis system, including CAD, CAE, Design for Six Sigma (DFSS), etc. The purpose of governance of process was to maximize to develop continuously both internal and external skills and capabilities as part of knowledge integration and accumulation. One of the most effective factors effected knowledge sharing and diffusion was enhancing the quality of interfaces and communication.

COMAC used a collaborative innovation center and competitive intelligence program covering a wide range of knowledge from external source to drive aircraft development. However, these external knowledge sources were not systematically incorporated. Some reasons were that many suppliers and research institutions came from Aviation 
Industry Corporation of China (AVIC), which competed directly with COMAC in some aeronautic products and projects. To some extent, there was a reluctance to accept for COMAC as other organizations and institutions may have superior knowledge in specific areas of expertise. Consequently, it was necessary to identify the organizational units (divisions) within COMAC which interacted with suppliers and were involved in "supplier development" activities. This was done by interviewing general managers of strategy department and project department to identify and understand multi-lateral knowledge transfer "routines" among COMAC and its suppliers. For main suppliers or sub-suppliers from both national and international, the first assignment in Co-NPD network was to arrange $\mathrm{R} \& \mathrm{D}$, manufacture, and delivery as stipulated in the contract. Of course, some divisional committees and top committees were designed to allow for communication and identification with design information, experience exchange, production quality through implementation of lean production systems promoted in COMAC and its suppliers. Ties among members facilitated the transfer of explicit knowledge easily in the Co-NPD network.

COMAC also formed a number of formal partnerships with universities to share knowledge in complex innovative technology for NPD of aircraft. It can learn and absorb new knowledge and practices by virtual laboratory to solve the genetic distance problems. It can also benefit from a long history and accumulation of academic knowledge by training, consulting, or working with numerous universities. In addition, customers, generally referring to airline companies, as one of important participants should be involved as early as possible with user insights. The role of customers in knowledge portal was R\&D process involvement, problem feedback from user insights, and aircraft repair assistants. While the customers were involved in the R\&D process, they can redefine the cause of design problems according their experience and hand over the problem solving process to an appropriate division(s) within Co-NPD network. Sometimes, COMAC not only upgraded the skills of $\mathrm{R} \& \mathrm{D}$, but also achieved better results ahead of schedule.

\section{KNOWLEDGE INTEGRATION ARCHITECTURE IN CO-NPD NETWORK OF AIRCRAFT}

This paper showed that Co-NPD network with the central of knowledge repository of C919 program formed key infrastructure to enable the knowledge integration process. However, how to actualize the actors share their knowledge to accelerate NPD process was not easy to realize. From the experience of large-scale new product development, multi-layered models were frequently observed. So, Multi-layered knowledge integration architecture in Co-NPD of large commercial aircraft was explored as following Fig. 2. With the Co-NPD multi-layered model, professionals in various departments and specialist fields, including overall architectural design of the targeted development products, design of each subsystem, software and hardware development, collaboration at each management level, went on to form hierarchies. Knowledge portal can be analyzed in multiple subsystems comprise of layered structures. Additionally, there also existed interfaces and relationships across multi-levels.

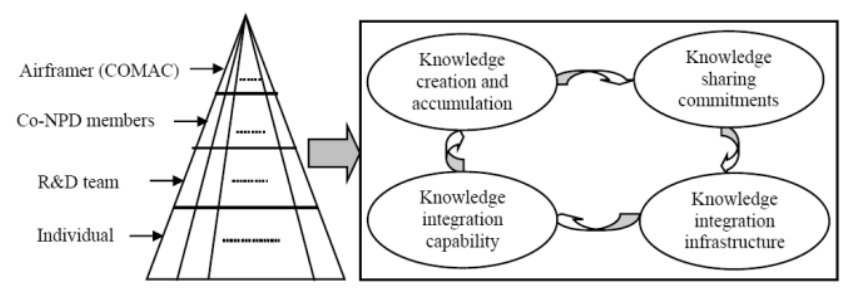

Fig. 2. Multi-layered knowledge integration architecture in Co-NPD of large commercial aircraft.

The first level comprised a team of leaders (top management) in charge of related divisions at COMAC, and they had complete authority to formulate and execute new aircraft product and service development. The second level comprised the collaborators including suppliers, universities and academic institutions, and customers. They were responsible for new technology and modules development according to contracts. The third level acted as bridges comprised a team of technicians and senior middle managers from each participant in Co-NPD network that examined connectivity and cooperation among actors in system architecture and solved plenty of complex problems. The basic level was comprised of many staff to accomplish detailed design and development assignments forming the core of aircraft product development. In this kind of multi-layered architecture, technicians and professionals provided the creativity and flexibility needed to present professional task to the mission. Meanwhile, the hierarchy structure had the advantage of guaranteeing efficiency and rapid decision-making when implementing specific tasks.

At each level of the hierarchy structure, knowledge integration process always occurred from knowledge creation and accumulation and finished with this goal. In order to increase the ability of Co-NPD network to accumulate and build on its stock of valuable knowledge, COMAC had created knowledge repository for acquiring, storing, and diffusion production know-how. By creating knowledge repository that was tasked with accumulating knowledge which resided within Co-NPD network, each member easily knew where to find different types of knowledge so it reduced its search costs. Knowledge sharing within the network was an essential condition to achieve knowledge integration. Effective factors to promote knowledge sharing in the Co-NPD process can be summarized: the willingness of knowledge sharing, complementary of knowledge resources, difficulty of knowledge sharing, and risk of opportunism behaviors. The willingness of knowledge sharing presented the attitude and collaboration commitment of actors to participate the Co-NPD. The complementary of knowledge resources indicated the participants can obtain the knowledge resources and skills easily and inexpensively in the Co-NPD network. The difficulty of knowledge sharing meant the obstacles and challenges at sharing knowledge supported by information systems, techniques and other infrastructures. The risk of opportunism behaviors can highly disturb the trust and collaboration relationships among enterprises in the Co-NPD network. In COMAC, it built 10-15 communities of practice supported its knowledge sharing and integration 
strategy. It also developed relative software to serve knowledge integration behaviors. These communities were classified into three types: organization-oriented communities, which included people who had the tasks in different divisions It was not necessarily a gathering of all procurements, but it could be a gathering of all those who were willing to sharing their experience and problems. The second was process-oriented communities, which included people in the same process from various firms or academic institutions. The last was technology-oriented communities, which included people who dealt with the same technology and R\&D assignment that were parts of aircraft development. All aspects of promoting knowledge integration consisted a knowledge flow loop, and the feedback mechanism can help improve the knowledge integration capabilities, and ultimately achieve the mission.

\section{INTERFACES AND COLLABORATIVE MECHANISMS WITHIN THE MULTI-LAYERED MODEL}

According to the interviews, we found that there existed different interfaces among different levels of knowledge integration and the collaborative mechanisms within these interfaces. Look at the interfaces found at COMAC, we were able to distinguish three types of interfaces: interfaces within Co-NPD network; interfaces between organizations and the $\mathrm{R} \& \mathrm{D}$ teams; interfaces within the R\&D team members that deal with innovative aspects. Table 1 showed the interfaces of the COMAC categorization according to the three types of interfaces.

The different types of interfaces within the Co-NPD network supported routes of knowledge (both explicit and tacit) communication, diffusion and use freely in the network. This allowed for a "matching" of the types of knowledge with the most efficient manner possible. Individual members were able to develop embedded ties with other members that have particularly relevant knowledge. Further, the different types of interfaces allowed for multi-lateral transfers of tacit knowledge on a particular topic/knowledge domain. Thus, there were a variety of complex processes through which members can choose to receive, or integrate different types of knowledge. Additionally, COMAC, as the central company, designed some collaborative mechanisms and regulations to promote the actors integrating different types of knowledge for each type of interface, shown as Table 2. At the beginning of designing the collaborative mechanisms, COMAC was also faced with a fundamental dilemma which was how to provide assurance to participants that proprietary knowledge would be protected while at the same time encourage participants to contribute valuable knowledge to members of Co-NPD network. COMAC created some regulations of reciprocal knowledge sharing within Co-NPD network by providing free assistance to all participants and giving them different authorities to access to knowledge repository of C919 program. The premise was that actors must be willing to open their plants to other network members if they chose to receive COMAC consulting assistance and/or participate in core groups. Therefore, by creating these norms and collaborative mechanisms, specific knowledge in Co-NPD network realized to be effectively protected and fully utilized.

TABLE I: INTERFACES CATEGORIZED INTO THREE TYPES WITHIN THE

\begin{tabular}{|c|c|}
\hline \multicolumn{2}{|c|}{ MulTI-LAYERED MODEL } \\
\hline Type of interfaces & Interface \\
\hline $\begin{array}{l}\text { Interfaces within } \\
\text { Co-NPD network }\end{array}$ & $\begin{array}{l}\text { The interfaces between COMAC } \\
\text { and their suppliers } \\
\text { The interfaces between COMAC } \\
\text { and academic institutions } \\
\text { The interfaces between COMAC } \\
\text { and customers } \\
\text { The collaboration process between } \\
\text { COMAC and consulting }\end{array}$ \\
\hline $\begin{array}{l}\text { Interfaces between } \\
\text { organizations and } \\
\text { R\&D teams }\end{array}$ & $\begin{array}{l}\text { The interfaces between top } \\
\text { managers and R\&D teams } \\
\text { The interfaces between leaders of } \\
\text { subsystems and R\&D teams }\end{array}$ \\
\hline $\begin{array}{l}\text { Interfaces within the } \\
\text { R\&D team members }\end{array}$ & $\begin{array}{l}\text { The interfaces between technicians } \\
\text { of R\&D teams } \\
\text { The interfaces between members in } \\
\text { general topic committees }\end{array}$ \\
\hline
\end{tabular}

TABLE II: COLLABORATIVE MECHANISMS WITHIN THE THREE TYPES OF

\begin{tabular}{|c|c|}
\hline Type of interfaces & Knowledge to be integrated \\
\hline $\begin{array}{l}\text { Interfaces within } \\
\text { Co-NPD network }\end{array}$ & $\begin{array}{l}\text { General knowledge about designed } \\
\text { subsystems } \\
\text { Procedural knowledge about how to use } \\
\text { knowledge portal and tools } \\
\text { Specialized knowledge domain from } \\
\text { Co-NPD actors }\end{array}$ \\
\hline $\begin{array}{l}\text { Interfaces between } \\
\text { organizations and } \\
\text { R\&D teams }\end{array}$ & $\begin{array}{l}\text { Procedural knowledge about task } \\
\text { dependencies and responsibilities } \\
\text { Efficiency of information processing } \\
\text { Rigor schedule of project planning }\end{array}$ \\
\hline $\begin{array}{l}\text { Interfaces within the } \\
\text { R\&D team members }\end{array}$ & $\begin{array}{l}\text { Detailed knowledge about each other's } \\
\text { design (task) and process } \\
\text { Special skills or experience of } \\
\text { technicians about a design (task) }\end{array}$ \\
\hline
\end{tabular}

\section{CONCLUSIONS AND FUTURE RESEARCH}

The need for effective knowledge integration is a key drive for collaborative NPD, especially for high technology NPD such as the aircraft products. The study seeks to contribute to the role of knowledge management within Co-NPD through the case of the R\&D activities of large commercial aircraft of China. It can be concluded that there is a need to incorporate and codify internal and external knowledge using both organizational and IT based approaches, with appropriate organizational architecture and collaborative norms support. From an organizational perspective, there is a need for Co-NPD structures to be informed by systematic embedding of both external and internal knowledge. The external knowledge can be obtained through benchmarking partnerships. Internal knowledge needs to be facilitated through effective management support and communication across functional sharing of knowledge. So, this paper explored a knowledge integration portal for acquisition, integration, and sharing knowledge with the central of knowledge repository of aircraft program. The knowledge portal was analyzed in multiple subsystems comprised of multi-layered structure like as many cases of large-scale new 
product development and major projects. In the multi-layered knowledge integration architecture, there existed different types of interfaces and collaborative mechanism to develop embedded ties among actors. Within each interface, the aim of collaborative mechanisms is to create the norms for both effectively protecting "proprietary knowledge" and maximizing knowledge sharing.

In particular, for anyone interested in related topics, research in the future may be approached in the following directions: 1) May take a step further and consider the characteristic of multiple stages, research what factors affect the R\&D process from a knowledge management perspective. 2) May take a step further and consider how to design norms and performance measurements to motivate interfirm employee and suppliers to search for new technologies and methods to improve. Propose a more scientific method to make the study more comprehensive to help the R\&D process of Chinese large aircraft achieve the challenging goals.

\section{ACKNOWLEDGMENT}

This paper was supported by Humanities and Social Science Foundation of Education Ministry of China under Grant 13YJC630085.

\section{REFERENCES}

[1] T. S. Davenport and L. Prusak, Working knowledge: How organizations manage what the know, Boston, MA: Harvard Business School Press, pp. 196-197, 2000.

[2] B. Rappert, A. Webster, and D. Charles, "Making sense of diversity and reluctance: Academic-Industrial relations and intellectual property," Research Policy, vol. 28, no. 8, pp. 873-890, 1999.

[3] A. Mishra and R. Shah, "In union lies strength: Collaborative competence in new product development and its performance effects," Journal of Operations Management, vol. 27, no. 4, pp. 324-338, 2009.
[4] D. J. Ayers, G. L. Gordon, and D. D. Schoenbachler, "Integration and new product development success: The role of formal and informal controls," Journal of Applied Business Research, vol. 17, no. 2, pp. 133-148, 2011.

[5] L. Bstieler, "Trust formation in collaborative new product development," Journal of Product Innovation Management, vol. 23, no. 1, pp. 56-72, 2006

[6] P. K. Lam and K. S. Chin, "Identifying and prioritizing critical success factors for conflict management in collaborative new product development," Industrial Marketing Management, vol. 34, no. 8, pp. 761-772, 2005.

[7] K. M. Bartol and A. Srivastava, "Encouraging knowledge sharing: The role of organizational reward systems," Journal of leadership \& Organizational Studies, vol. 9, no. 1, pp. 64-76, 2002.

[8] M. S. Liu and N. C. Liu, "Sources of knowledge acquisition and patterns of knowledge sharing behaviors: An empirical study of Taiwanese high tech firms," International Journal of Knowledge Management, vol. 28, no. 5, pp. 423-432, 2008.

[9] M. Kleinsmann, J. Buijs, and R. Valkenburg, "Understanding the complexity of knowledge integration in collaborative new product development teams: A case study," Journal of Engineering and Technology Management, vol. 27, no. 1-2, pp. 20-32, 2010.

[10] A. H. Bond and R. J. Ricci, "Cooperation in aircraft design," Research in Engineering Design, vol. 4, no. 2, pp. 115-130, 1992.

[11] R. McAdam, T. O'Hare, and S. Moffett, "Collaborative knowledge sharing in composite new prodcut development: An aerospace study," Technovation, vol. 28, no. 5, pp. 245-256, 2008.

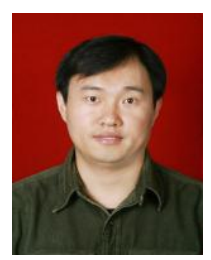

Li Zhengfeng is a lecturer of management science in the School of Management at Northwestern Polytechnica University. He holds a BA in marketing, and a MS in enterprise management, and a $\mathrm{PhD}$ in management science and engineering from the Northwestern Polytechnical University, China. As a joint doctoral candidate, he studied and researched in University of Technology of Troyes of France for one year. His research interests include knowledge management, and technology innovation. He has more than 20 papers appeared in journals and conferences. 